\title{
Conventional tooth supported overdenture: A case report
}

Kharel B ${ }^{1}$, Rai A ${ }^{2}$, Suwal P3 , Parajuli $\mathrm{PK}^{4}$, Limbu I ${ }^{5}$, Basnet $\mathrm{BB}^{6}$

${ }^{1,2}$ PG Resident, Department of Prosthodontics and Crown-Bridge, BPKIHS, Dharan, Nepal.

${ }^{3}$ Professor, Department of Prosthodontics and Crown-Bridge, BPKIHS, Dharan, Nepal.

${ }^{4}$ Associate Professor, Department of Prosthodontics and Crown-Bridge, BPKIHS, Dharan, Nepal.

${ }^{5,6}$ Assistant Professor, Department of Prosthodontics and Crown-Bridge, BPKIHS, Dharan, Nepal.

\begin{abstract}
The present prime concern in dentistry is on preservation of remaining natural teeth. Presence of few teeth in oral cavity help in preserving alveolar ridge integrity, maintain the proprioception, and gives psychological benefit to the patient. Overdenture has proven to be the mainstay of conservative prosthodontic treatment when proper diagnosis, treatment planning, and most importantly, patient compliance are achieved. This paper presents a case report of rehabilitation of a 65 year old patient with multiple missing teeth with tooth supported overdenture in both maxilla and mandible.
\end{abstract}

Key words: Edentulism; overdenture; residual ridge resorption.

\section{Introduction}

$\mathrm{R}$ emoval of all natural teeth and wearing of complete dentures for a long time generally results in alveolar bone loss. The presence of few remaining teeth has shown to have lesser amount of residual ridge resorption. ${ }^{1}$ Extraction of entire dentitions followed by complete denture replacements leads to psychological trauma, reduced stability, retention, compromised masticatory function and undermined esthetic appearance. ${ }^{2}$ Preservation of few natural teeth also helps in maintenance of proprioceptive ability of periodontium and gives psychological benefit to the patient which in turn evidenced significantly better masticatory performance. ${ }^{3}$ An overdenture is defined as any removable dental prosthesis that covers and rests on one or more remaining natural teeth, the roots of natural

\section{Conflict of Interest: No}

\section{*Corresponding Author}

Dr. Bharat Kharel, PG Resident

Department of Prosthodontics and Crown-Bridge,

BPKIHS, Dharan, Nepal

E-mail: kharelbharat211@gmail.com teeth, and/or dental implants; a dental prosthesis that covers and is partially supported by natural teeth, natural tooth roots, and/or dental implants. ${ }^{4}$ Although tooth supported overdenture requires a careful case selection, planning and execution, it has been an economically feasible alternative to implant supported overdenture.

\section{Case Report}

A 65-year old male patient was self-referred to the Department of Prosthodontics, College of Dental Surgery, BPKIHS with a chief complaint of difficulty in chewing food and poor appearance and wanted replacement of missing teeth. The patient had multiple carious and missing teeth. In radiographic examination, 13 and 23 in maxillary arch and 33 and 43 in the mandibular arch revealed good bone support and long roots. Primary impression was made with alginate and diagnostic casts were mounted in a nonadjustable articulator. The vertical dimension of the patient was adequate for overdenture with short copings. Extraction of all hopeless teeth were carried out. Endodontic treatment of the canines was subsequently performed. 
After the intentional root canal treatment of all four teeth (Figure 1), they were prepared with tapered round end diamond point with a chamfer finish line (Figure 2). Impression was made with additional silicone (Aquasil, Dentsply) for the fabrication of copings. The copings (Figure 3) obtained were checked for fit in the patient's mouth and finally cemented with glass ionomer cement (Gold label, GC Corporation).

Primary impressions for the maxillary and mandibular arches were made with alginate (Zelgan, Dentsply). The impressions were poured and special trays were fabricated with self-cure acrylic resin with double spacer over abutment teeth. Border molding was done for both the arches with low fusing compound (DPI Pinnacle, DPI). Final impressions for the maxillary and mandibular arches (Figure 4) were made with light body addition silicones (Reprosil, Dentsply). Master casts were prepared by pouring the impressions in Type IV

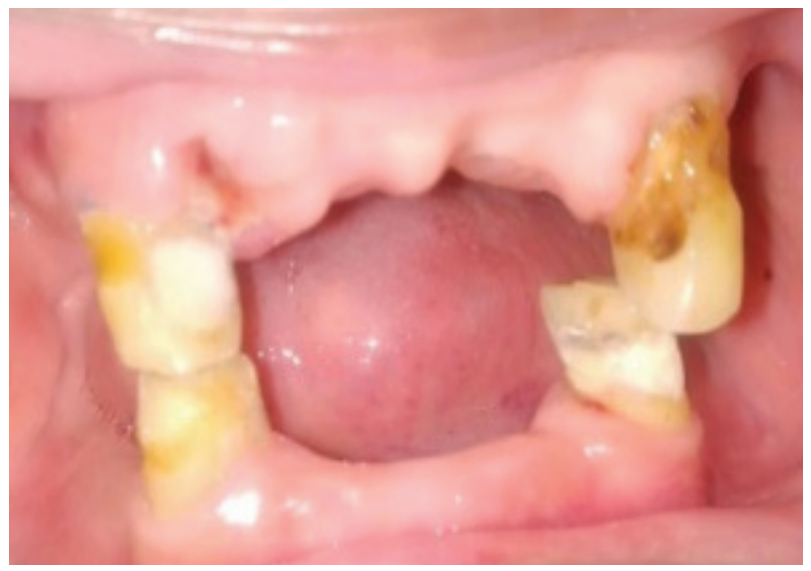

Figure 1: Initial situation

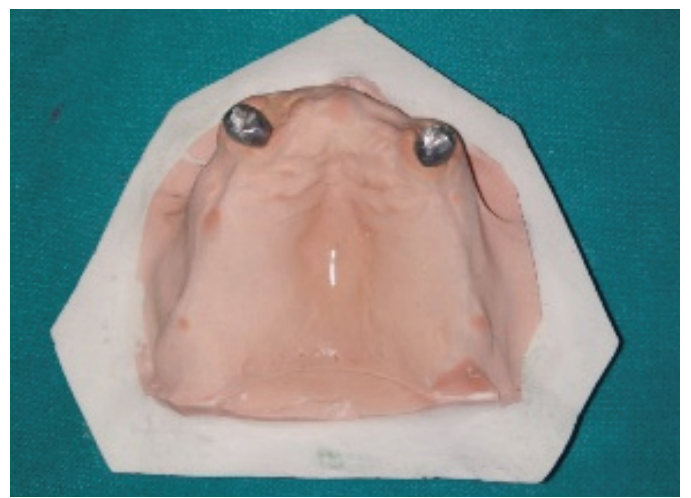

Figure 3: Short coping fabrication gypsum products (Kalrock, Kalabhai Products).

Fabrication of record bases was done after the application of separating medium and copings were covered with wax. Fabrication of occlusal rims was done; jaw relations were recorded and transferred onto the Hanau wide-view semi adjustable articulator (Prestige Dental, UK) with the help of spring-bow (Figure 5).

Teeth arrangement was done and evaluated in the patient's mouth for phonetics, vertical and centric relation, and esthetics (Figure 6). Vertical dimension was verified and also centric and eccentric contacts were checked. Patient's approval was taken, and the curing of the final denture was done in acrylic resin (Trevalon, Dentsply). The denture was cured, polished and inserted. Clear post-insertion instructions regarding denture and abutment teeth were given to the patient. Post-insertion adjustments were made after 24 hours. The patient was recalled for periodic follow up.

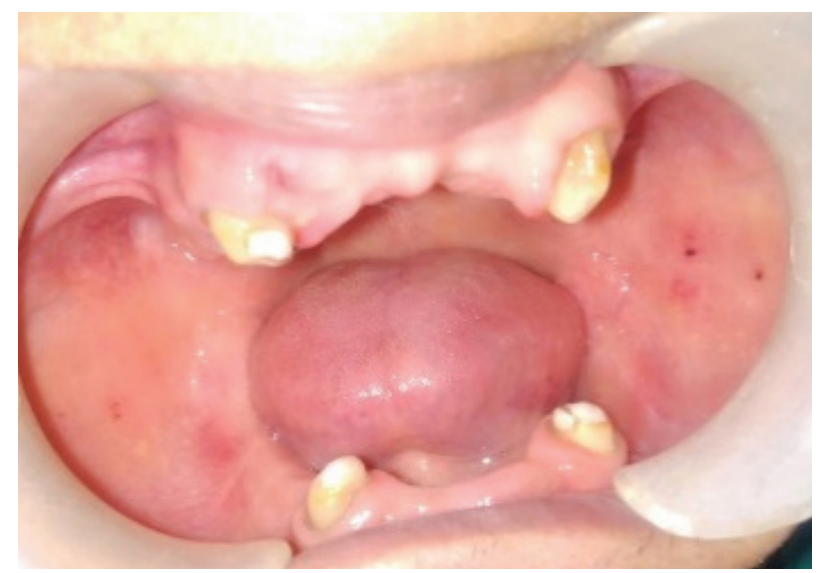

Figure 2: Tooth preparation

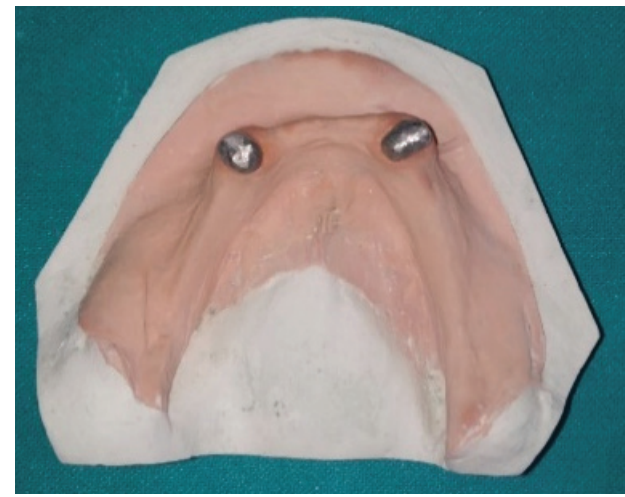

Journal of Nepalese Prosthodontic Society (JNPS) 


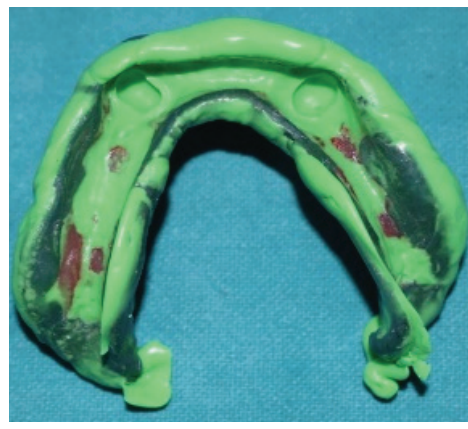

Figure 4: Secondary impression
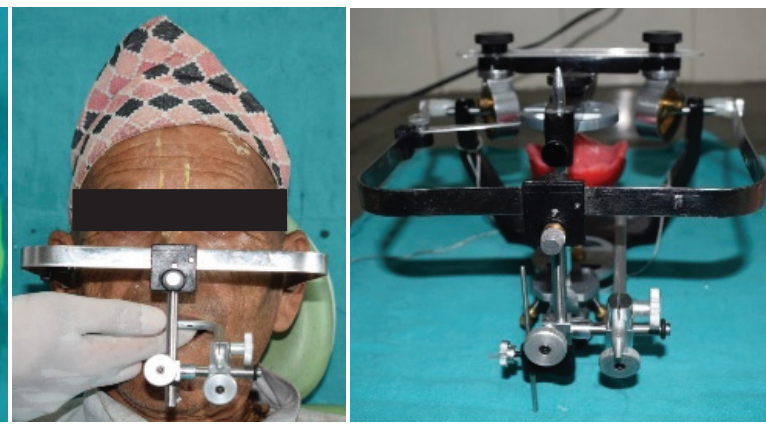

Figure 5: Face bow transfer

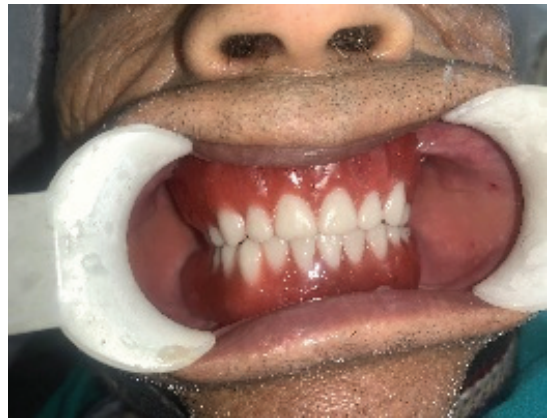

Figure 6: Try in

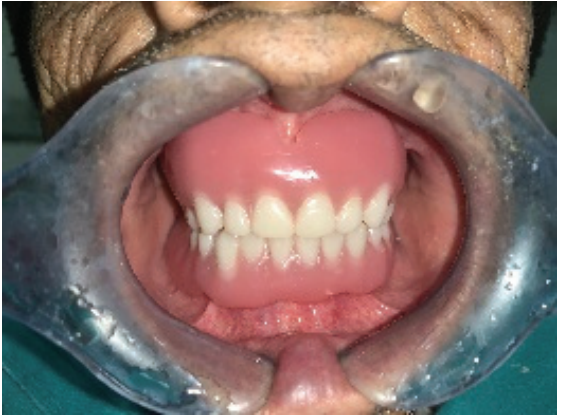

Figure 7: Insertion

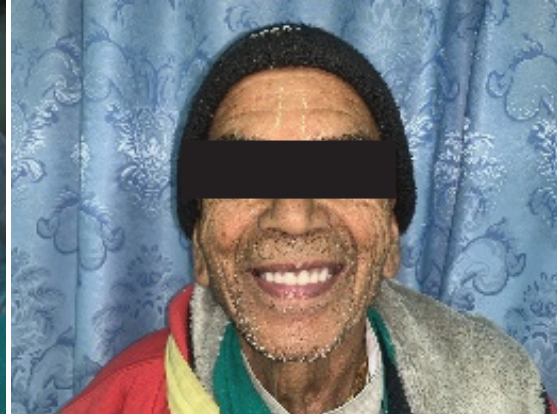

\section{Discussion}

Tooth supported overdenture is a simple, yet cost effective preventive prosthodontic treatment. Tooth supported overdenture provides a psychological advantage over conventional denture and a cost effective alternative to implant supported overdentures. Proprioception, presence of directional sensitivity; dimensional discrimination; canine response and tactile sensitivity are maintained in tooth supported overdentures. ${ }^{5}$ Rissin et al., in 1978, compared masticatory efficiency of natural dentition, conventional complete denture, and overdenture and found that overdenture patients, when compared to complete denture patients, while chewing a test food for a constant number of strokes, expended an equivalent amount of muscle effort, chewed more slowly and efficiently, and evidenced significantly better masticatory performance by producing an increased volume of fine test food particles. ${ }^{3}$ Generally, two canines are used because of their strategic location in the arch. If a choice between an anterior or a posterior tooth must be made, the anterior tooth should be selected as the anterior teeth are located in a portion of the arch that is generally more susceptible to tissue loss. The tooth supported overdenture technique should not be reserved for use only in the mandibular arch; the procedure can be used in the maxilla. ${ }^{6}$

Various techniques used in the treatment of teeth to serve as abutment for overdenture ranges from simple tooth modification and reduction, tooth preparation with cast coping to endodontic therapy with amalgam plug or cast coping utilizing some form of attachments. ${ }^{7}$ In our case, we have used short metal copings which are comparatively economical solutions and help prevent abutment fractures by distributing more of the occlusal load on the residual alveolar ridge and less on the abutment. ${ }^{8}$

The patient should be motivated to properly maintain the retained teeth with home care and understand the importance of periodic followup care by the dentist. ${ }^{9}$ 
While there is compelling evidence that implant retained and/or supported prostheses are in many ways superior to conventional complete dentures and would represent the standard of care for edentulous individuals, the majority of them are poor and will never be candidates for implant therapy. ${ }^{10}$ The simplest solution would be avoiding extraction of all teeth and keeping a few teeth for a tooth supported overdenture.

\section{Conclusion}

Tooth supported overdentures can be used in both maxillary and mandibular arches. In addition to improved proprioception and reduced alveolar ridge resorption, they also increase the stability of the prosthesis. However, proper planning before the execution and periodic follow up after insertion are required for long term success of the prosthesis.

\section{References}

1. Crum RJ, Rooney GE. Alveolar bone loss in overdentures: A 5-year study. J Prosthet Dent. 1978;40(6):610-3.

2. Zarb GA, Bolender CL. Prosthodontic Treatment for Edentulous Patients. In: 11th ed. St Louis ,Mosby: Elsevier; 2013. p. 6-23, 16076, 190-208.
3. Rissin L, House JE, Manly RS, Kapur KK. Clinical comparison of masticatory performance and electromyographic activity of patients with complete dentures, overdentures, and natural teeth. J Prosthet Dent. 1978;39(5):508-11.

4. Driscoll CF, Freilich MA, Guckes AD, Knoernschild KL, Mcgarry TJ. The Glossary of Prosthodontic Terms: Ninth Edition. J Prosthet Dent. 2017;117(5):e1-105.

5. Manly RS, Pfaffman C, Lathrop DD, Keyser J. Oral sensory thresholds of persons with natural and artificial dentitions. J Dent Res. 1952;31(3):305-12.

6. Zamikoff II. Overdentures--theory and technique. J Am Dent Assoc. 1973;86(4):8537.

7. Henking JPA. Overdentures. J Dent. 1982;10(3):217-25.

8. Warren AB, Caputo AA. Load transfer to alveolar bone as influenced by abutment designs for tooth-supported dentures. J Prosthet Dent. 1975;33(2):137-48.

9. Toolson LB, Smith DE. A five-year longitudinal study of patients treated with overdentures. J Prosthet Dent. 1983;49(6):749-56.

10. Carlsson GE, Omar R. The future of complete dentures in oral rehabilitation. A critical review. J Oral Rehabil. 2010;37(2):143-56. 